\title{
Collaborative Tools in the Primary Classroom: Teachers' Thoughts on Wikis
}

\author{
Andria Agesilaou, Christiana Vassiliou, Sotiroula Irakleous, and Maria Zenios \\ Cyprus University of Technology, Limassol, Cyprus \\ \{agesilaou.andria, christivass, irakleoussotiroula, \\ mkzenios\} @gmail.com
}

\begin{abstract}
The purpose of this work-in-progress study is to examine the attitudes of primary school teachers in Cyprus on the use of wikis as a mean to promote collaborative learning in the classroom. A survey investigation was undertaken using 20 questionnaires and 3 semi-structured interviews. The survey results indicate a positive attitude of teachers in Cyprus to integrate wikis in primary education for the promotion of cooperation. As such collaborative learning activities among pupils are being encouraged.
\end{abstract}

Keywords: wikis, primary education, collaboration, collaborative learning, educators.

\section{Introduction}

By upgrading the Web from Web 1.0 to Web 2.0, various and different tools appeared in the online space. One of the most popular technological tools is the wiki [10]. Wikis are a popular tool with many possibilities, which we see embodied in many areas of human life. Education is one of the places where wikis find perfect fit, according to experimental studies have been done [4].

Higher education primarily led the way for inclusion of this multimedia tool in the learning process, as a means of promoting the co-construction of knowledge among students. Although its use is spreading widely in schools, however, elementary education is presently out of this application. Moreover, there are few studies done to study this aspect [10]. Based on the assumption that wikis are used for implementation of educational objectives it is expected that sooner or later they will become integrated into primary education.

The purpose of this research, therefore, is to contribute to the literature on the use of wikis in primary education and to form a complete picture of the attitudes of Cypriot primary school teachers for: (a) the wikis as a tool for collaborative learning and (b) as a tool that they intend to use in the future in their teaching work.

Among the concepts of solidarity, mutual respect and mutual help, educationalists wish to instill in children the concept of cooperation. In order to cultivate a spirit of cooperation among students, an approach that starts from the early learning years is needed. For this reason, the primary school teachers have a very important role in achieving this goal. It is vital to promote cooperation rather than competition among 
students. The wikis can offer collaborative environments capable, through their structure and features, to support the co-construction of knowledge by students and contribute to the completion of cooperative activities [4-10].

\section{$2 \quad$ Research Questions}

1. What are the attitudes of primary school teachers for promoting collaborative learning in the context of formal education through the use of wikis?

2. Are primary school teachers willing to use the wiki in their classroom for activities promoting cooperation and targeted learning?

3. In what way, according to the views of teachers, the use of wikis within primary education can help students to processing collaborative projects?

4. What should be the role of the teacher during the use of a wiki for collaborative processing projects for students, according to the views of primary school teachers?

\section{Methods}

\subsection{Research Procedure}

The study is based on a mixed approach for the data collection. Specifically, quantitative and qualitative methodology is used in order to crosscheck the data and achieve valid and reliable results. The data collection tools were a questionnaire consisting of 29 questions and a semi structured interview. The questionnaire consists of four parts, and includes closed questions and open-ended. The first two parts, include the closed questions, the third part includes open-ended questions and finally the fourth part refers to demographic questions, to examine whether the factor of sex or experience in primary education, influence the opinions of teachers. Firstly, we gave the questionnaire to the participants and when the procedure was completed, we started the interviews. The analysis of the questionnaires was made through Microsoft Office Excel using tables and charts and the analysis of the interviews followed the qualitative content analysis.

\subsection{Research Participants}

Participants of the study were working teachers in public sector education, and specifically in public primary schools. Twenty teachers ( 7 men and 13 women) aged 26 and above took part in the study. The average of the years participants had been working in schools is 11,6 years. An important element of the sample selection was the experience of teachers, so we avoided reaching out to primary teachers who did not practice the profession. The sample of this study is characterized as a convenience sample and we ought to make clear that it was not in our first criteria not to include participants from the private education sector, but it was something that came up after. From the sample of 20 participants, we selected three of them for the procedure of the interview. 


\section{$4 \quad$ Literature Review}

Cooperation is an essential skill that should characterize both adults and kids. The last years, great efforts are made to integrate cooperation activities into the educational system, since cooperation is considered a necessary skill for the integral development of the person (Partnership for 21st century skills, 2009; Kay, 2011). The advantage of this cooperation implies the integration of cooperative learning in an education system, which should base its operation on a model that meets the 21 st century [5].

As al result, learners initially are characterized by a host of skills of the time and point of readiness, since they can cope with the demands of society [10].

Dillenbourg defines collaborative learning as "a situation in which two or more people learn or are in the process of learning something together." [3] [page. 1]. One definition [1] states that "cooperative learning is a system of learning methods, in which students work with interaction and interdependence in small heterogeneous groups to achieve common goals" [page 61]. The existence of a group of people is necessary, in order to achieve learning through communication between them, either in person-contact, whether in an asynchronous or synchronous discussion via a mobile device [3].

The concept of cooperation ensures central role in Web 2.0 technologies, since these technologies are characterized by various factors such as interaction, active user participation and communication between them at any time and any place [10]. As a Web 2.0 technology, wikis are characterized as collaborative learning tools that promote cooperation [10]. It is worth mentioning that the word wiki comes from the Hawaiian "wiki wiki", which means that something is done quickly [13].

\subsection{Features of Wikis}

There are certain unique characteristics that can be used to describe this technology. Through the wiki the user can create content and then edit it in a collaborative way. Users may add, delete and change the content of the wiki in which they are members. Additionally, wiki gives them the potential of asynchronous discussion, which gives them the opportunity of reflection and critical thinking on the content, by any user separately in its own time and space [10].

\subsection{Teacher Role}

The characteristics of wikis although differ depending on usage, the owners and the architecture of the page, are believed to have the potential as a technology to enhance collaborative activities and be a source of knowledge and learning space [11]. Prerequisite for the proper and complete use of wikis is the knowledge around this technological tool on the part of teachers [4]. Teachers should help in their own way, so that each child feels comfortable to the idea of use of a wiki in the learning process [8]. In education, however, should be emphasized and the role of the teacher to use technology, to apply it correctly and produce the desired results. The role of the teacher is to guide the collaborative knowledge building [10]. 
The wiki, being a tool for carrying out cooperative activities, allows the teacher to observe how students organize and coordinate their cooperation to solve a problem, and thus achieve a project [7]. It is important that the teacher will seek to carry out a collaborative activity through the use of the wiki, be well aware of the capabilities and features of this technology in order to prepare and train their students properly. This process takes time and students should practise not abruptly, but gradually and methodically. Research states that the educational use of wikis is based on the preferred learning model of education [2].

\subsection{Learner Role}

Through wikis, students assume new roles, which in traditional teaching could not be possible to have. In roles like the one of the producer, content is created by the student. They can also act as commentator enabled by the functionality of the wiki to comment and reflect on data posted from others in a wiki. Finally there is the role of the classifier, since each member of a wiki has to classify the activity. These roles characterize the users of a wiki [13]. As a result of these different roles, users are given the opportunity for the organization and construction of knowledge. Corollary of this is the association of wikis with the theory of social constructivism of Vygotsky [13].

An additional requirement for the use of wikis, relates to the fact that the users need to participate actively in collaborative writing, therefore they must have developed the ability of expressing themselves very well. This will eventually enable the active involvement of learners in the process of problem solving and constructive cooperation between them [10]. Research emphasizes that through a tool such as a wiki, one can form groups of students, which will be invited to create content through cooperation with each other, exchanging ideas and opinions on the subject they are studying and developing skills of autonomy and responsibility for their own personal learning [4].

\subsection{Social Constructivism}

Social constructivism, according to Vygotsky, emphasizes on student interaction for building and creating their own learning and knowledge [12]. Two models of learning that meet the characteristics and capabilities of a wiki, is constructivism and collaborative learning [2]. Both of these models do not follow traditional methods of teaching where the teacher is an authority and the student passive receiver of information and knowledge.

According to the principles of social constructivism, opportunities exist for students to develop concepts based on their prior knowledge and understanding. It is necessary, therefore, to have appropriate tools that will allow students to discover new knowledge and support them in their efforts in a creative way [2]. 


\subsection{Wikis and Learning Communities}

Research indicates that successful use of a technological tool such as the wiki needs to develop a framework of intersubjectivity [10]. Within a collaborative wiki one may create teach communities, which can be compared to learning experiences that are gained as part of participation and negotiation" [4]. An indispensable factor for the successful creation of learning communities is intersubjectivity when creating content that will be hosted by the wiki. There must be an exchange of views and ideas, interaction and negotiation between participants that identify the elements considered under all members group, and thus will be incorporated in their field [10].

It is worth noting that according to earlier research wikis create communities of practice that are identified as particularly important to the educational process [13]. Theory reinforces the importance of communities of practice, indicating that interaction between individual experience and social cognitive structures may result in knowledge creation [13]. This collaborative process of building knowledge in a wiki, leads to the creation of so-called "architecture of participation", after users students, collaborate and interact to produce and compose the subject of their study. In line with the views of teachers who studied the capabilities of a wiki, this can facilitate learning by creating a learner-centered educational process [13].

\subsection{Challenges}

Like any technological tool, and so wikis, have to face various challenges in the effort to integrate them into the educational process. When handling a collaborative activity in a wiki, the risk that users-learners focus more on the technological tool, rather than to the study topic-problem which is called upon to resolve, exists. Meanwhile, a wiki hardly presents the individual's work, which can create confusion for the distinct roles that every member of a team has to carry. It should also be noted that the production of content by any user is not considered guaranteed within a wiki, since there can be no absolute accuracy of the content generated by each separately. These challenges, however, can be overcome by promoting the idea that the contribution of each team member is considered equally important in the process of studying a subject through a wiki [8].

The various challenges of wikis were considered in a survey conducted in higher education [11]. The latter aimed to determine whether the use of wikis in collaborative learning environments, as part of learning the Japanese language at an early stage was helpful and contributed in blended learning scenarios where face-toface contact and interaction through technology were combined. Research indicated emerging challenges such as the difficulty in creating and modifying the content of a page wiki, the uncertainty about the nature of activities undertaken, difficulties on deciding the structure that should be followed, and the need for more direct interaction within groups and issues about leadership among team members [11].

Cooperation may be both a catalytic and a limiting factor in achieving a common goal, as on the one hand, students can recognize the positive results from the use of technology in learning and on the other, the difficulties on the process followed at 
several points, depending on the weaknesses that characterize each part of the wiki. This may be due to lack of adequate training in techniques involving the wiki and student information from the teacher to the stage and type of activities that should be carried out [11]. Some of these challenges stem from the lack of effective coordination for the work done and the different time and space cooperation takes place in an environment wiki [7].

Research on the integration of wikis as a collaborative learning tool in primary education, revealed that the characteristics of the particular technological tool fosters cooperation between learners, even young school children [13]. Users of wikis characterized by anxiety about the criticism they would receive from the rest of what had been written. Teachers are the ones who have to reduce the stress levels of the students and to emphasize that the main objective of processing an activity in a wiki, is a form of collaboration between users, which requires honesty and sharing thoughts and ideas [13].

The wikis seems to offer opportunities for developing the important skills of cooperation and integration of knowledge, which are required by learners of all ages.

\section{Discussion}

The analysis of the data showed some really important findings. To begin with the first research question that is related to the attitudes of primary school teachers about wikis and the collaboration learning, positive attitude is identified. Most of the teachers who participated in the research and specifically 14 out of the 20 participants agreed with the statement that the use of wiki leads to collaboration when it is used in the classroom. The same positive attitude is noted from the participants about the use of wiki and collaboration outside of the classroom door (13 out of 20 were positive). Only one participant disagreed with the statement that wikis results to collaboration when they are used outside the classroom. A positive attitude is observed in total due to the educators who believe that the use of wikis leads in the achievement of collaborative learning.

Furthermore, the second research question which refers to the degree of availability of teachers to use the wiki in the classroom mainly for the implementation of group assignments, a positive attitude is identified as well. We found that 15 out of the 20 participants showed positive attitudes about the use of wiki in their own classroom and about the attainment of group work. Only one participant showed negative attitude with the use of wiki in his own classroom for team work.

Continuing with the third research question relating with primary school student's willingness to implement team work using wikis based to the technological features of them, results indicate that teachers are willing to try them in their classrooms. More specifically primary school educators have noted the characteristics of the wikis which make group work flexible and feasible. Features as the asynchronous discussion, the content editing, the post of multimedia content from the students, characteristics noted by earlier research [4 -10] make the use of wiki really important for the achievement of collaborative learning. In summary, educators believe that 
wikis facilitate team work and the "entrance" of them in the classroom will be good for the children, due to the fact that collaboration skills will be approved and the group work will be based on interaction between students.

The last research question refers to the role of the educator in the classroom when wikis are the means to achieve group assignments. Our 20 informants agree on their views on the role of the teacher. They believe that teachers must have the leading role when wiki is used, indicating that educators have to participate with their students during the process of collaborative learning through wikis. They also suggest that they have to give feedback to the students at regular time intervals. Specifically six out of the 20 participants completely agreed with the statement that the teacher has to have the leading role. Moreover, 12 of the 20 teachers also agreed with the specific statement. Also, 15 teachers agreed with the statement that during the process of the use of wiki and the implementation of assignments, educators have to give general and specific feedback to the students. These characteristics of the teacher role are also mentioned in the literature [8].

These results that derived from the analysis of the questionnaire data were compared with the data collected from the semi-structured interviews. In total three interviews were taken. Through the qualitative analysis of the interviews, the same positive attitude is shown from the teachers. It is worth noting, however, that through the interviews some problems were referred from the participants about the use of wiki in Cyprus classrooms. First of all, the one interviewee noted the lack of computers and in general the lack of technological equipment in Cyprus schools, that makes the use of wiki difficult. Further, another problem expressed by the second interviewee refers to the lack of time in the classroom. The uses of wikis were considered to be too time consuming for an overloaded curriculum. The third interviewee said that despite the fact that wiki technology is very important and the use of it will result in collaborative learning, one needs to specify the characteristics that students must have to achieve this. Appreciation to the work of others, discussion with the group you work with about the content of the assignment, respect to all the members of the team and communication between the students were among the qualities required from the students.

In summary, the analysis of the semi-structure interviews emphasized the positive attitude of educators about wikis. Interviews also pointed the vital role the teachers must have during the implement of assignments using wiki technology. They further highlighted the main problems that are likely occurring from the use of wiki in a typical Cyprus classroom. These mainly relate to the lack of infrastructure in schools, the time pressures and overloaded curriculum which specifies the material educators have to cover in a specific time schedule as indicated by the Ministry of Education and Culture of Cyprus.

\section{Conclusion}

The ultimate purpose of conducting the current research was to examine the views of primary school teachers in Cyprus about wikis as a tool that can be integrated into 
education and promote collaborative learning. The importance of this work-inprogress study lies in its attempt to illuminate the field of wiki use in Cyprus primary schools and teachers' views in particular.

Results indicate that the teachers have a quite positive attitude towards the use of wikis in primary education, since according to their views they promote collaboration among students and learning outcomes based on the implementation of the learning objectives set on each lesson. Also in accordance with their views, wikis and the ways in which they work lead to the development of collaborative skills to students.

Further, teachers appear to be willing to incorporate wikis into the learning process, for achieving objectives in different subject domains of the curriculum. Teachers note, however, difficulties exist in the introduction of wikis in Cypriot primary education, the main reasons being logistical and related to infrastructure in schools and lack of time on the part of teachers to cover the teaching material.

Finally, despite their positive attitudes, teachers stress the importance of equity in the integration of wikis in education. They believe that their role in processes of collaborative learning enabled through the use of wikis should be prescriptive, with continued participation and feedback to learners to maximize learning.

Implications of the study point to the need to consider the use of wikis in the primary classroom as part of collaborative learning activities. Further study needs to explore further questions on teacher attitudes and existing uses of wikis in larger populations in Cyprus schools.

\section{References}

1. Charalampous, N.: Collaborative Learning: from theory to practice. Pedagogical Institute of Cyprus (2000), http://users.sch.gr/kliapis/NeofytF.pdf (retrieved);

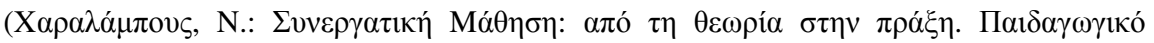

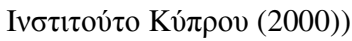

2. Cole, M.: Using Wiki technology to support student engagement: Lessons from the trenches. Computers \& Education 52(1), 141-146 (2009)

3. Dillenbourg, P.: Introduction: What do you mean by 'collaborative learning'? In: Dillenbourg, P. (ed.) Collaborative learning: Cognitive and computational approaches. Pergamon/Elsevier Science Ltd., Oxford (1999)

4. Grant, L.: Using Wikis in Schools: a Case Study, Futurelab, 1-10 (2006)

5. Kay, K.: 21st century skills: why they matter, what they are, and how we get there. In: Bellanca, J., Brandt, R. (eds.) 21st Century Skills. Rethinking How Students Learn, pp. xiii-xxxi. Solution Tree Press, Bloomington (2011)

6. Korompili, S. (n.d.): The need for guiding strategy in libraries of educational institutions, pp. 109-116, http://eprints.rclis.org/10707/1/14psab018.pdf (retrieved)

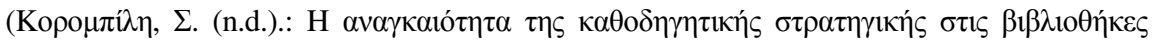

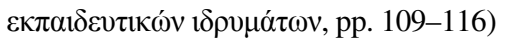

7. Larusson, J.A., Alterman, R.: Wikis to support the "collaborative" part of collaborative learning. International Journal of Computer-Supported Collaborative Learning 4, 371-402 (2009) 
8. O'Bannon, B.W., Lubke, J.K., Britt, V.G.: You still need that face-to-face communication.: drawing implications from preservice teachers' perceptions of wikis as a collaborative tool. Technology, Pedagogy and Education, 1-18 (2013)

9. Partnership for 21 st Century skills Framework definitions (2009), http: / / 21 .org / storage/documents/P21_Framework_Definitions.pdf (retrieved)

10. Pifarré, M., Staarman, J.: Wiki-supported collaborative learning in primary education: How a dialogic space is created for thinking together. International Journal of ComputerSupported Collaborative Learning 6(2), 187-205 (2011)

11. Ramanau, R., Geng, F.: Researching the use of Wiki's to facilitate group work. Procedia Social and Behavioral Sciences 1(1), 2620-2626 (2009)

12. Schunk, D. Learning Theories: An Educational Approach. Athens: Metaixmio. (2010)

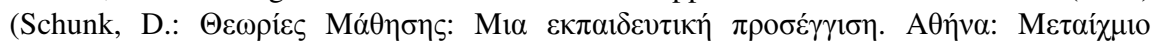
(2010))

13. Wheeler, S., Yeomans, P., Wheeler, D.: The good, the bad and the wiki: Evaluating student-generated content for collaborative learning. British Journal of Educational Technology 39(6), 987-995 (2008) 